\title{
Early cognitive and emotional outcome after stroke is independent of discharge destination
}

\author{
Jos P. L. Slenders ${ }^{1}$ - Daan P. J. Verberne ${ }^{2}$ (D) Johanna M. A. Visser-Meily ${ }^{3,4} \cdot$ Renske M. Van den Berg-Vos ${ }^{1,5}$. \\ Vincent I. H. Kwa ${ }^{1}$ Caroline M. van Heugten ${ }^{2,6}$
}

Received: 23 March 2020 / Revised: 10 June 2020 / Accepted: 12 June 2020 / Published online: 24 June 2020

(c) The Author(s) 2020

\begin{abstract}
Background and purpose Cognitive and emotional problems occur frequently after stroke. Patients with minor stroke are more likely to be discharged home. This paper compares early cognitive and emotional outcomes in patients discharged home after stroke versus patients discharged to inpatient rehabilitation, and examines the effect of cognitive and emotional outcomes on long-term participation.

Methods In this multicenter prospective cohort study, patients with stroke were assessed at two months with the Hospital Anxiety and Depression Scale (HADS), the Checklist for Cognitive and Emotional Consequences following Stroke (CLCE24) and the Montreal Cognitive Assessment (MoCA). One year post stroke, participation was assessed with the Restriction subscale of the Utrecht Scale for Evaluation of Rehabilitation-Participation (USER-P Restriction).

Results The study included 332 patients. Two months post stroke, anxiety and cognitive problems were equally prevalent among patients discharged home $(n=243 ; 73 \%)$ and patients discharged to inpatient rehabilitation $(n=89 ; 27 \%)$ (HADS-A $=4.8 \pm 3.9$ versus $4.6 \pm 4.0, p=0.747$; $\mathrm{MoCA}<26: 66.7 \%$ versus 70.8\%, $p=0.477$; CLCE-cognition $=3.0 \pm 2.9$ versus $3.3 \pm 2.8, p=0.499$ ). Depressive symptoms were less severe in patients discharged home (HADS-D $=4.3 \pm 3.9$ versus $5.5 \pm 3.8, p=0.010$ ). In patients discharged home, cognitive complaints were predictive of long-term participation $(B=-2.03 ; 95 \% \mathrm{CI}-3.15,-0.90)$, while cognitive or emotional outcomes were not predictive in patients discharged to inpatient rehabilitation.

Conclusions Cognitive and emotional problems at two months post stroke were comparable between patients discharged home and those discharged to inpatient rehabilitation. For patients discharged home, cognitive complaints were predictive of long-term participation.
\end{abstract}

Keywords Cerebrovascular disease/stroke $\cdot$ Cognition $\cdot$ Anxiety and depression $\cdot$ Participation

\section{Introduction}

Jos P. L. Slenders and Daan P. J. Verberne contributed equally to this work.

\footnotetext{
Caroline M. van Heugten

c.vanheugten@maastrichtuniversity.nl

1 Department of Neurology, OLVG, Amsterdam, The Netherlands

2 Department of Psychiatry and Neuropsychology, Maastricht University, Maastricht, The Netherlands

3 Department of Rehabilitation, Physical Therapy Science and Sports, UMC Utrecht Brain Center, University Medical Center Utrecht, Utrecht, The Netherlands
}

Center Utrecht, Utrecht, The Netherlands
Global incidence and prevalence of stroke are both high, leaving many patients disabled [1-4]. Discharge destination after hospital admission is largely determined by functional

4 Center of Excellence for Rehabilitation Medicine, UMC Utrecht Brain Center, University Medical Center Utrecht, and De Hoogstraat Rehabilitation, Utrecht, The Netherlands

5 Department of Neurology, Amsterdam UMC, Amsterdam, The Netherlands

6 Department of Neuropsychology and Psychopharmacology, Maastricht University, PO Box 616, 6200 MD Maastricht, The Netherlands 
dependence and the level of physical disability [5]. Patients who have suffered a minor stroke are more likely to be considered functionally independent and will most likely be discharged home directly, whereas patients with a major stroke are more likely to be discharged to inpatient rehabilitation [6]. After inpatient rehabilitation, the vast majority of these patients will also be discharged home. Recent developments in the acute care for ischemic stroke show decreases in the level of physical disability [7, 8]. As a result, the number of so-called 'walking and talking' patients (i.e. patients with relatively good neurological recovery) is increasing and more patients are being discharged home directly $[9,10]$.

Besides physical disability, cognitive and emotional problems are frequent after stroke, among both patients with major and minor strokes $[11,12]$. These problems can negatively affect participation (for example in household activities, return to work or social activities), which is an important outcome of stroke care and an essential goal in stroke rehabilitation [13]. Screening and treatment for cognitive and emotional problems is an integral part of inpatient rehabilitation, whereas this type of treatment is possibly less commonly offered to patients who are discharged home [14]. As these problems are less obvious than physical disability, recognition and effective follow-up care might be lacking in patients recovering at home, even though they may also need follow-up care $[15,16]$. To the best of our knowledge, no direct comparison has been made of cognitive and emotional outcomes in the early phase after stroke between patients discharged home and those discharged to inpatient rehabilitation.

This study aimed to compare early cognitive and emotional problems after stroke in patients discharged home versus patients discharged to inpatient rehabilitation. Additionally, the effects of early cognitive and emotional outcomes on participation at one year post stroke were examined in both groups, while controlling for demographic and stroke characteristics.

\section{Methods}

\section{Design and procedure}

The current study concerns secondary analyses of the Restore4stroke Cohort, a multicenter prospective longitudinal cohort study conducted in six general hospitals in the Netherlands [17]. Patients were included between March 2011 and March 2013.

The Restore4stroke study consisted of five assessments from stroke onset up to 24 months post stroke. The current study used data from within the first week (T1) and two months (T2) and one year (T3) post stroke. When eligibility criteria were met and written informed consent had been obtained, research nurses extracted demographic and medical information from the medical charts after one week. The assessment, including a cognitive assessment at two months, was performed by a trained research assistant. The assessment at one year consisted solely of questionnaires and was completed by the patient on paper or online. The protocol has been described in more detail elsewhere [17].

\section{Participants}

Patients with a clinical diagnosis of stroke (either ischemic or hemorrhagic) in the past seven days, as confirmed by a neurologist, were considered eligible. Patients were excluded if one of the following was present: (1) comorbidity interfering with the study outcomes, (2) dependence in activities of daily living (ADL) before the stroke, as defined by a Barthel Index (BI) score of 17 or lower, (3) insufficient command of the Dutch language, based on clinical judgement, and (4) cognitive decline as defined by a score of one or higher on the Heteroanamnesis List Cognition before their stroke [18].

\section{Measures}

\section{Demographics and stroke characteristics}

Demographic information included sex, age, marital status, discharge destination and level of education according to the Dutch classification system developed by Verhage [19]. Stroke characteristics included stroke severity, measured by the National Institutes of Health Stroke Scale (NIHSS) [20]. Functional dependence in ADL was measured by the BI, with a total score ranging from zero to 20; higher scores are indicative of greater independence in ADL [21]. Patients discharged home were defined as those being discharged home directly after their hospital stay and still living at home after two months. All others were discharged to inpatient rehabilitation (including geriatric rehabilitation) with the aim of living at home again within three to six months after the diagnosis was made.

\section{Cognitive functioning}

The Montreal Cognitive Assessment (MoCA) was used to screen for the presence of cognitive disorders. The MoCA consists of ten items with a total score ranging from 0 to 30 . A higher score reflects a better performance. A score $<26$ was regarded as cognitive impairment [22]. The MoCA was completed by a trained research assistant. 


\section{Cognitive and emotional complaints}

The Checklist for Cognitive and Emotional Consequences following Stroke (CLCE-24) is a patient-reported outcome measure. It was used to assess the number of cognitive and emotional complaints in daily life and was completed by a trained research assistant. The cognitive domain (CLCE-24 cognition) consists of 13 items (ranging from 0 to 13) and the emotional domain (CLCE-24 emotion) of nine items (ranging from 0 to 9). The instrument includes two blank items in case other problems are present which are not mentioned in the list of common consequences. All items are scored as 'absent (0)' or 'present (1)' ('present' or 'doubtful') [23].

\section{Anxiety and depression}

The Hospital Anxiety and Depression Scale (HADS) was used to assess the severity of symptoms of anxiety and depression. The HADS includes seven items for both the anxiety (HADS-A) and depression (HADS-D) subdomains, resulting in 14 items in total. Each item is rated on a fourpoint scale (0-3) and a higher score reflects more severe symptoms. Both subdomain scores range from 0 to 21 . 'No symptoms' was defined as a score $<8$ for each subdomain and 'mild to severe symptoms of depression or anxiety' was defined as a score $\geq 8[24,25]$.

\section{Participation}

The Restriction subscale of the Utrecht Scale for Evaluation of Rehabilitation-Participation (USER-P Restriction) was used to measure if subdomains of participation (e.g. 'work' or 'relationship') could be performed 'independently without difficulty', 'with difficulty', 'with assistance' or 'cannot be performed'. The USER-P Restriction consists of 11 items and compares the current situation with the situation before the stroke for each item. The sum of the items is converted to a 0-100 scale, with a higher score reflecting less restrictions [26]. The USER-P Restriction has previously demonstrated satisfactory validity and reliability, and it has excellent responsiveness in patients after stroke [27-29].

\section{Statistical analyses}

All patients who completed the MoCA, CLCE-24 and HADS at two months were included in this analysis. Patients were divided into those discharged home and those discharged to inpatient rehabilitation.

Demographics and stroke-related information were recorded. Marital status was recorded as being or not being in a relationship. Type of stroke was recorded as ischemic or hemorrhagic stroke. Educational level was dichotomized into 'low' $(\leq 5)$ versus 'high' $(\geq 6$; i.e. completed higher professional education or university) based on the Dutch classification system developed by Verhage [19]. Selection bias analyses were performed in which included patients and excluded patients (with missing data at two months) were compared on demographic and stroke-related information. Independent samples $t$ tests were performed to examine the differences between the two groups at two months on the MoCA, CLCE-24 cognition, CLCE-24 emotion, HADS-A and HADS-D. Pearson chi-square statistics were used to examine differences in percentages of patients with a HADSA and HADS-D above the cutoff points and MoCA below the cutoff point.

Restrictions in participation one year after stroke, measured by the USER-P Restriction, were dichotomized into 'no restrictions' ('independently without difficulty') and 'restrictions' ('with difficulty', 'with assistance' or 'cannot be performed') and were analyzed using descriptive statistics.

Next, the association of the predictors of interest, viz. the MoCA, CLCE-24 cognition, CLCE-24 emotion, HADS-A and HADS-D scores, with USER-P Restriction at one year were examined using univariable linear regression. A multivariable model was used to analyze significantly associated predictors of interest. Besides the significantly associated predictors of interest, the multivariable model was adjusted for the following pre-specified demographic and strokerelated covariates: sex, age at stroke, marital status, educational level, type of stroke, stroke severity as measured with the NIHSS, functional dependence as measured with the BI, and length of hospital stay in days. The univariable associations and multivariable models were performed separately for the patients discharged home and those discharged to inpatient rehabilitation.

The assumptions of linearity, independent errors, homoscedasticity, and normally distributed errors were checked. A $p$ value of 0.05 was used to determine statistical significance. IBM SPSS version 25.0 was used for analyses.

\section{Results}

\section{Characteristics}

The Restore4stroke Cohort study included 395 patients. Sixty-three patients were excluded because MoCA, CLCE24 or HADS data at two months were missing. A total of 332 patients with complete data were included in the current analysis. Baseline data of these patients are presented in Table 1. Excluded patients $(n=63)$ had a significantly higher NIHSS score $(4.2 \pm 4.2 ; p=0.004)$ and a significantly lower BI $(15.0 \pm 4.4 ; p=0.002)$ than the group of included patients. 
Table 1 Baseline characteristics of the total group and specified for discharge destination

\begin{tabular}{|c|c|c|c|c|}
\hline & Total group $(n=332)$ & $\begin{array}{l}\text { Discharged home } \\
(n=243)\end{array}$ & $\begin{array}{l}\text { Discharged to inpatient reha- } \\
\text { bilitation }(n=89)\end{array}$ & $p$ value \\
\hline Sex (\% male $)$ & 64.5 & 66.7 & 58.4 & 0.165 \\
\hline Age in years $($ mean $\pm \mathrm{SD})$ & $66.7 \pm 12.3$ & $65.2 \pm 11.8$ & $70.7 \pm 12.9$ & $<0.001$ \\
\hline Marital status (\% in relationship) & 68.7 & 76.1 & 48.3 & $<0.001$ \\
\hline High education level (\%) & 26.2 & 28.0 & 21.3 & 0.223 \\
\hline Ischemic stroke (\%) & 93.1 & 94.2 & 89.9 & 0.256 \\
\hline Location of stroke & & & & 0.077 \\
\hline Left hemisphere (\%) & 40.5 & 43.8 & 31.8 & \\
\hline Right hemisphere (\%) & 42.4 & 38.3 & 53.4 & \\
\hline Vertebrobasilar (\%) & 16.1 & 17.9 & 14.8 & \\
\hline First stroke (\%) & 87.0 & 86.0 & 89.9 & 0.722 \\
\hline NIHSS $($ mean \pm SD) & $2.5 \pm 2.9$ & $1.7 \pm 2.2$ & $4.6 \pm 3.7$ & $<0.001$ \\
\hline $\mathrm{BI}($ mean $\pm \mathrm{SD})$ & $17.2 \pm 4.4$ & $18.8 \pm 2.5$ & $12.7 \pm 5.3$ & $<0.001$ \\
\hline Length of hospital stay in days (mean \pm SD) & $8.5 \pm 6.4$ & $6.3 \pm 3.7$ & $14.5 \pm 8.1$ & $<0.001$ \\
\hline
\end{tabular}

SD standard deviation, NIHSS National Institutes of Health Stroke Scale, BI Barthel Index

Of the total group, 243 (73\%) were discharged home and $89(27 \%)$ were discharged to inpatient rehabilitation. The group of patients discharged home was significantly younger, had a lower NIHSS score, a higher BI score, and a shorter hospital stay, and was significantly more likely to be in a relationship $(p<0.05)$ (Table 1). Of the patients who were discharged to inpatient rehabilitation, $92 \%$ were living at home after one year; the remaining $8 \%$ were living at inpatient rehabilitation at one year.

\section{Comparison of cognitive and emotional consequences at two months after stroke}

The results of the MoCA, CLCE-24 cognition, CLCE-24 emotion and HADS-A assessments at two months did not differ significantly between the patients discharged home and those discharged to inpatient rehabilitation (Table 2). Patients discharged to inpatient rehabilitation scored significantly higher on the HADS-D than those discharged home $(5.5 \pm 3.8$ versus $4.3 \pm 3.9)$. The proportion of cognitively impaired patients with a score $<26$ on the MoCA did not differ significantly between the two groups. The proportions of patients with above-cutoff scores on the HADS-A and HADS-D did not differ significantly between groups either.

\section{Restrictions in participation one year after stroke}

Table 3 displays the level of patient-reported restrictions in participation at one year for each of the subdomains. Overall, patients discharged to inpatient rehabilitation experienced more restrictions in participation after one year. The four most affected domains in both groups were paid/unpaid work or education, sports and physical exercise, household activities and day trips.
Table 2 Cognitive and emotional outcomes at two months in patients discharged home and patients discharged to inpatient rehabilitation group

\begin{tabular}{llll}
\hline & $\begin{array}{l}\text { Discharged home } \\
(n=243)\end{array}$ & $\begin{array}{l}\text { Discharged to inpatient reha- } \\
\text { bilitation }(n=89)\end{array}$ & $p$ value \\
\hline MoCA (mean \pm SD) & $23.8 \pm 3.8$ & $22.9 \pm 4.1$ & 0.067 \\
$\%$ MoCA $<26$ cutoff & 66.7 & 70.8 & 0.477 \\
CLCE-24 cognition (mean \pm SD) & $3.0 \pm 2.9$ & $3.3 \pm 2.8$ & 0.499 \\
CLCE-24 emotion (mean \pm SD) & $2.8 \pm 1.9$ & $3.0 \pm 1.8$ & 0.451 \\
HADS-D (mean \pm SD) & $4.3 \pm 3.9$ & $5.5 \pm 3.8$ & 0.010 \\
HADS-A (mean \pm SD) & $4.8 \pm 3.9$ & $4.6 \pm 4.0$ & 0.747 \\
\%HADS-D $\geq 8$ cutoff & 19.3 & 25.8 & 0.198 \\
$\%$ HADS-A $\geq 8$ cutoff & 19.3 & 21.3 & 0.685 \\
\hline
\end{tabular}

MoCA Montreal Cognitive Assessment, CLCE-24 Checklist for Cognitive and Emotional Consequences following Stroke, HADS Hospital Anxiety and Depression Scale 
Table 3 Restrictions in participation after one year for the total group

\begin{tabular}{lllllc}
\hline Items & \multicolumn{2}{l}{ Discharged home $(n=243)$} & & $\begin{array}{l}\text { Discharged to inpatient reha- } \\
\text { bilitation }(n=89)\end{array}$ \\
\cline { 2 - 3 } & $n$ & $\begin{array}{c}\text { \% of patients experienc- } \\
\text { ing restrictions }\end{array}$ & & $\begin{array}{c}\text { \% of patients expe- } \\
\text { riencing restric- } \\
\text { tions }\end{array}$ \\
\hline Paid/unpaid work/education & 90 & 46.7 & & 18 & 83.3 \\
Household activities & 199 & 42.2 & 68 & 80.9 \\
Outside activities & 202 & 33.2 & 71 & 59.2 \\
Sports/physical exercise & 188 & 47.9 & 62 & 75.8 \\
Going out & 161 & 34.8 & 54 & 68.5 \\
Day trips & 180 & 40.0 & 65 & 80.0 \\
Leisure activities & 193 & 22.8 & 74 & 39.2 \\
Relationship with partner & 163 & 30.1 & 35 & 57.1 \\
Visiting friends & 202 & 30.7 & 68 & 58.8 \\
Receiving visitors & 205 & 18.5 & 69 & 30.4 \\
Contact online or by telephone & 200 & 17.0 & 72 & 22.2 \\
\hline
\end{tabular}

\section{Predictive value of cognitive and emotional problems on participation in patients discharged home}

Univariable linear regression for patients discharged home showed that the MoCA, CLCE-24 cognition, CLCE-24 emotion, HADS-A and HADS-D scores were significantly associated with USER-P Restriction scores (for participation) at one year $(p<0.05)$ (Table 4$)$. Multivariable linear regression, adjusted for sex, age at stroke, marital status, educational level, type of stroke, stroke severity as measured with the NIHSS, functional dependence as measured with the BI, and length of hospital stay in days, showed that only CLCE-24 cognition scores and the covariate of age had a significant negative effect on participation at one year. The MoCA, CLCE-24 emotion, HADS-A and HADS-D scores were not significantly predictive of participation at one year.

\section{Predictive value of cognitive and emotional problems on participation in patients discharged to inpatient rehabilitation}

In the inpatient rehabilitation group, none of the predictors of interest proved to be significantly predictive of USER-P

Table 4 Linear regression: effects of emotional and cognitive problems at two months on participation at one year after stroke

\begin{tabular}{|c|c|c|c|c|c|c|}
\hline \multirow{3}{*}{$\begin{array}{l}\text { Predictors at two months } \\
\text { post stroke }\end{array}$} & \multicolumn{6}{|c|}{ USER-P Restrictions at one year post stroke } \\
\hline & \multicolumn{3}{|l|}{ Univariable analyses } & \multicolumn{3}{|l|}{ Multivariable analysis $^{\mathrm{a}}$} \\
\hline & B $(95 \%$ CI $)$ & SE & $p$ value & B $(95 \%$ CI $)$ & SE & $p$ value \\
\hline \multicolumn{7}{|c|}{ Patients discharged home directly } \\
\hline MoCA & $1.394(0.712$ to 2.076$)$ & 0.346 & $<0.001$ & $0.555(-0.144$ to 1.255$)$ & 0.355 & 0.119 \\
\hline CLCE-24 cognition & $-3.017(-3.787$ to -2.248$)$ & 0.390 & $<0.001$ & $-2.025(-3.153$ to -0.897$)$ & 0.572 & $<0.001$ \\
\hline CLCE-24 emotion & $-3.508(-4.722$ to -2.294$)$ & 0.616 & $<0.001$ & $-0.014(-1.653$ to 1.625$)$ & 0.831 & 0.987 \\
\hline HADS-D & $-2.048(-2.611$ to -1.485$)$ & 0.285 & $<0.001$ & $-0.743(-1.681$ to 0.195$)$ & 0.476 & 0.120 \\
\hline HADS-A & $-1.926(-1.926$ to -1.324$)$ & 0.305 & $<0.001$ & $-0.527(-1.433$ to 0.379$)$ & 0.459 & 0.252 \\
\hline \multicolumn{7}{|c|}{ Patients discharged to inpatient rehabilitation } \\
\hline MoCA & $0.410(-0.688$ to 1.508$)$ & 0.551 & 0.459 & NA & - & - \\
\hline CLCE-24 cognition & $0.104(-1.547$ to 1.755$)$ & 0.829 & 0.901 & NA & - & - \\
\hline CLCE-24 emotion & $-0.359(-2.904$ to 2.185$)$ & 1.278 & 0.779 & NA & - & - \\
\hline HADS-D & $-0.158(-1.312$ to 0.995$)$ & 0.579 & 0.785 & NA & - & - \\
\hline HADS-A & $-0.017(-1.079$ to 1.113$)$ & 0.550 & 0.976 & NA & - & - \\
\hline
\end{tabular}

$C I$ confidence interval, $C L C E-24$ Checklist for Cognitive and Emotional Consequences following Stroke, HADS Hospital Anxiety and Depression Scale, MoCA Montreal Cognitive Assessment, NA not applicable, SE standard error

${ }^{a}$ Adjusted for sex, age at stroke, marital status, educational level, type of stroke, NIHSS, BI and length of hospital stay in days 
Restriction scores in univariable linear regression (Table 4). As a consequence, no multivariable analysis was performed for the inpatient rehabilitation group.

\section{Discussion}

Remarkably, this study showed that cognitive problems and symptoms of anxiety and depression are comparable at two months after stroke for patients discharged home and patients discharged to inpatient rehabilitation. We further found that, in patients discharged home, cognitive complaints at two months after stroke were predictive of participation restrictions at one year after stroke, when adjusted for demographic and stroke characteristics, including stroke severity. In patients discharged to inpatient rehabilitation, none of the cognitive or emotional scores were predictive of participation at one year.

After stroke, whether a patient is discharged home or to inpatient rehabilitation predominantly depends on functional dependence: the ability of a person to carry out daily activities in a safe and autonomous manner [6]. Functional dependence, in turn, is highly dependent on the physical outcome after stroke [30]. However, the results presented in this article show that patients with relatively good physical outcome who are discharged home experienced just as many cognitive and emotional problems as patients discharged to inpatient rehabilitation. Apparently, cognitive and emotional outcomes were not closely related to stroke severity as defined by physical disability. This gives rise to the question whether stroke severity should be defined predominantly by physical disability.

The high prevalence of cognitive and emotional problems was remarkable. This high prevalence among all our stroke patients, whether with or without substantial physical disability, might be due to damage to the complex underlying neural network. Since optimal cognitive and emotional functioning is supported by an extensive neural network, any stroke is likely to influence this network and its functions [31-33].

Additionally, the current study shows that cognitive complaints were prognostic of long-term participation restrictions in patients discharged home, which is in line with a recently published systematic review [34]. However, the results of individual studies in this review were mixed, and the authors stated that this variation could be explained by the limited predictive value of general screening tools. This might explain why the MoCA (as a screening tool) was not predictive in the current study, whereas the patient-reported CLCE-24 cognition was. Apparently, cognitive complaints that do not interfere with functional dependence, do interfere with long-term participation. This sounds reasonable, since participation across multiple domains is highly complex and is associated with multitasking and time pressure in many instances. As such, optimal participation requires great effort in terms of cognitive and emotional functioning. For patients discharged to inpatient rehabilitation, none of the cognitive or emotional problems were associated with long-term participation. As an implication for clinical practice, the results of this study underline the recommendation to actively screen for cognitive and emotional problems in an early phase after stroke in all patients after stroke and for any postdischarge setting [35]. Early detection and management for cognitive and emotional problems has proven its efficacy in terms of clinical and cost-effectiveness in patients after cardiac arrest [36, 37]. Moreover, patients with cognitive problems can benefit from cognitive rehabilitation by learning compensational strategies, and patients with emotional problems can be treated by psychological interventions, such as cognitive behavioral therapy, and/or pharmacotherapy. Moreover, rehabilitation care (whether inpatient or outpatient) can improve participation, including return to work [38-40].

The strengths of this study are its prospective nature, as well as the multicenter design. In addition, it included a large group of patients who completed long-term follow-up measurements. Cognitive and emotional outcomes were measured with validated patient-reported and objective screening instruments. Since participation is one of the main priorities in stroke and rehabilitation care, understanding its predictors is highly relevant for clinical practice. A limitation of this study is that the majority of the study sample had suffered a minor stroke and the number of patients with hemorrhagic stroke was rather small, which limits the generalizability of findings to the whole stroke population. Second, the group discharged to inpatient rehabilitation was relatively small which reduced the statistical power of the analyses in this group.

\section{Conclusion}

In conclusion, a surprising finding of this study was that cognitive and emotional problems were equally prevalent and severe among patients discharged home directly and those discharged to inpatient rehabilitation after stroke. Multivariable regression analyses revealed that cognitive complaints were predictive of long-term participation restrictions in patients discharged home. These findings underline the guideline recommendations on screening and treatment for cognitive and emotional problems, including for patients with minor stroke who are discharged home.

Acknowledgements We would like to thank all participants for their contributions to this study. 
Author contributions JV and $\mathrm{CH}$ were responsible for the original Restore4stroke cohort study. JS, DV, JV and CH designed the study. JS and DV analyzed and interpreted the data. JS and DV drafted the manuscript. JV, RB, VK and $\mathrm{CH}$ advised on preparation of the manuscript. All authors contributed read, edited and approved the final version of the manuscript.

Funding The Restore4stroke cohort study was supported by the VSBfonds (Grant Number: 89000004) and coordinated by ZonMw (Dutch organization for Health Research and Development).

Data availability The data that support the findings of this study are available from the corresponding author upon reasonable request.

\section{Compliance with ethical standards}

Conflicts of interest The authors declare that they have no conflict of interest.

Ethics approval The Restore4stroke study complies with the Declaration of Helsinki and was approved by the Committee on Research involving Human Subjects of the St. Antonius Hospital in Nieuwegein (The Netherlands) and by the medical ethics committees of all participating hospitals.

Consent to participate Written informed consent was obtained from all participating patients.

Open Access This article is licensed under a Creative Commons Attribution 4.0 International License, which permits use, sharing, adaptation, distribution and reproduction in any medium or format, as long as you give appropriate credit to the original author(s) and the source, provide a link to the Creative Commons licence, and indicate if changes were made. The images or other third party material in this article are included in the article's Creative Commons licence, unless indicated otherwise in a credit line to the material. If material is not included in the article's Creative Commons licence and your intended use is not permitted by statutory regulation or exceeds the permitted use, you will need to obtain permission directly from the copyright holder. To view a copy of this licence, visit http://creativecommons.org/licenses/by/4.0/.

\section{References}

1. Feigin VL, Forouzanfar MH, Krishnamurthi R, Mensah GA, Connor M, Bennett DA, Moran AE, Sacco RL, Anderson L, Truelsen T, O'Donnell M, Venketasubramanian N, Barker-Collo S, Lawes CM, Wang W, Shinohara Y, Witt E, Ezzati M, Naghavi M, Murray C (2014) Global and regional burden of stroke during 1990-2010: findings from the Global Burden of Disease Study 2010. Lancet (London, England) 383(9913):245-254. https://doi.org/10.1016/ s0140-6736(13)61953-4

2. Sun JH, Tan L, Yu JT (2014) Post-stroke cognitive impairment: epidemiology, mechanisms and management. Ann Transl Med 2(8):80. https://doi.org/10.3978/j.issn.2305-5839.2014.08.05

3. Campbell Burton CA, Murray J, Holmes J, Astin F, Greenwood D, Knapp P (2013) Frequency of anxiety after stroke: a systematic review and meta-analysis of observational studies. Int $\mathbf{J}$ Stroke Off J Int Stroke Soc 8(7):545-559. https://doi.org/10.111 1/j.1747-4949.2012.00906.x
4. Miller EL, Murray L, Richards L, Zorowitz RD, Bakas T, Clark P, Billinger SA (2010) Comprehensive overview of nursing and interdisciplinary rehabilitation care of the stroke patient: a scientific statement from the American Heart Association. Stroke 41(10):2402-2448. https://doi.org/10.1161/STR.0b013e3181 e7512b

5. Winstein CJ, Stein J, Arena R, Bates B, Cherney LR, Cramer SC, Deruyter F, Eng JJ, Fisher B, Harvey RL, Lang CE, MacKayLyons M, Ottenbacher KJ, Pugh S, Reeves MJ, Richards LG, Stiers W, Zorowitz RD (2016) Guidelines for adult stroke rehabilitation and recovery: a guideline for healthcare professionals from the American Heart Association/American Stroke Association. Stroke 47(6):e98-e169. https://doi.org/10.1161/str.0000000000 000098

6. Thorpe ER, Garrett KB, Smith AM, Reneker JC, Phillips RS (2018) Outcome measure scores predict discharge destination in patients with acute and subacute stroke: a systematic review and series of meta-analyses. J Neurol Phys Ther JNPT 42(1):2-11. https://doi.org/10.1097/npt.0000000000000211

7. Emberson J, Lees KR, Lyden P, Blackwell L, Albers G, Bluhmki E, Brott T, Cohen G, Davis S, Donnan G, Grotta J, Howard G, Kaste M, Koga M, von Kummer R, Lansberg M, Lindley RI, Murray G, Olivot JM, Parsons M, Tilley B, Toni D, Toyoda K, Wahlgren N, Wardlaw J, Whiteley W, del Zoppo GJ, Baigent C, Sandercock P, Hacke W (2014) Effect of treatment delay, age, and stroke severity on the effects of intravenous thrombolysis with alteplase for acute ischaemic stroke: a meta-analysis of individual patient data from randomised trials. Lancet (London, England) 384(9958):1929-1935. https://doi.org/10.1016/s0140 -6736(14)60584-5

8. Balami JS, Sutherland BA, Edmunds LD, Grunwald IQ, Neuhaus AA, Hadley G, Karbalai H, Metcalf KA, DeLuca GC, Buchan AM (2015) A systematic review and meta-analysis of randomized controlled trials of endovascular thrombectomy compared with best medical treatment for acute ischemic stroke. Int J Stroke Off J Int Stroke Soc 10(8):1168-1178. https://doi. org/10.1111/ijs.12618

9. Saver JL, Fonarow GC, Smith EE, Reeves MJ, Grau-Sepulveda MV, Pan W, Olson DM, Hernandez AF, Peterson ED, Schwamm LH (2013) Time to treatment with intravenous tissue plasminogen activator and outcome from acute ischemic stroke. JAMA 309(23):2480-2488

10. Tate WJ, Polding LC, Kemp S, Mlynash M, Heit JJ, Marks MP, Albers GW, Lansberg MG (2019) Thrombectomy results in reduced hospital stay, more home-time, and more favorable living situations in DEFUSE 3. Stroke. https://doi.org/10.1161/strok eaha.119.025165

11. Moran GM, Fletcher B, Feltham MG, Calvert M, Sackley C, Marshall T (2014) Fatigue, psychological and cognitive impairment following transient ischaemic attack and minor stroke: a systematic review. Eur J Neurol 21(10):1258-1267. https://doi. org/10.1111/ene.12469

12. Jokinen H, Melkas S, Ylikoski R, Pohjasvaara T, Kaste M, Erkinjuntti T, Hietanen M (2015) Post-stroke cognitive impairment is common even after successful clinical recovery. Eur J Neurol 22(9):1288-1294. https://doi.org/10.1111/ene.12743

13. de Graaf JA, van Mierlo ML, Post MWM, Achterberg WP, Kappelle LJ, Visser-Meily JMA (2018) Long-term restrictions in participation in stroke survivors under and over 70 years of age. Disabil Rehabil 40(6):637-645. https://doi.org/10.1080/09638 288.2016.1271466

14. Chen T, Zhang B, Deng Y, Fan JC, Zhang L, Song F (2019) Longterm unmet needs after stroke: systematic review of evidence from survey studies. BMJ Open 9(5):e028137. https://doi.org/10.1136/ bmjopen-2018-028137 
15. Planton M, Peiffer S, Albucher JF, Barbeau EJ, Tardy J, Pastor J, Januel AC, Bezy C, Lemesle B, Puel M, Demonet JF, Chollet F, Pariente J (2012) Neuropsychological outcome after a first symptomatic ischaemic stroke with 'good recovery'. Eur J Neurol 19(2):212-219. https://doi.org/10.1111/j.1468-1331.2011.03450 .X

16. Edwards DF, Hahn MG, Baum CM, Perlmutter MS, Sheedy C, Dromerick AW (2006) Screening patients with stroke for rehabilitation needs: validation of the post-stroke rehabilitation guidelines. Neurorehabilit Neural Repair 20(1):42-48. https://doi. org/10.1177/1545968305283038

17. van Mierlo ML, van Heugten CM, Post MW, Lindeman E, de Kort PL, Visser-Meily JM (2014) A longitudinal cohort study on quality of life in stroke patients and their partners: Restore4Stroke Cohort. Int J Stroke Off J Int Stroke Soc 9(1):148-154. https://doi. org/10.1111/j.1747-4949.2012.00882.x

18. Meijer R, van Limbeek J, de Haan R (2006) Development of the Stroke-unit Discharge Guideline: choice of assessment instruments for prediction in the subacute phase post-stroke. Int J Rehabilit Res Internationale Zeitschrift fur Rehabilitationsforschung Revue internationale de recherches de readaptation 29(1):1-8. https://doi.org/10.1097/01.mrr.0000175269.59788.41

19. Verhage F (1964) Intelligence and age: study with dutch people aged 12-77. Van Gorcum, Assen

20. Brott T, Adams HP Jr, Olinger CP, Marler JR, Barsan WG, Biller J, Spilker J, Holleran R, Eberle R, Hertzberg V (1989) Measurements of acute cerebral infarction: a clinical examination scale. Stroke 20(7):864-870

21. Collin C, Wade D, Davies S, Horne V (1988) The Barthel ADL Index: a reliability study. Int Disability Stud 10(2):61-63

22. Nasreddine ZS, Phillips NA, Bedirian V, Charbonneau S, Whitehead V, Collin I, Cummings JL, Chertkow H (2005) The Montreal Cognitive Assessment, MoCA: a brief screening tool for mild cognitive impairment. J Am Geriatr Soc 53(4):695-699. https:// doi.org/10.1111/j.1532-5415.2005.53221.x

23. van Heugten C, Rasquin S, Winkens I, Beusmans G, Verhey F (2007) Checklist for cognitive and emotional consequences following stroke (CLCE-24): development, usability and quality of the self-report version. Clin Neurol Neurosurg 109(3):257-262. https://doi.org/10.1016/j.clineuro.2006.10.002

24. Zigmond AS, Snaith RP (1983) The hospital anxiety and depression scale. Acta Psychiatr Scand 67(6):361-370

25. Sagen U, Vik TG, Moum T, Mørland T, Finset A, Dammen T (2009) Screening for anxiety and depression after stroke: Comparison of the Hospital Anxiety and Depression Scale and the Montgomery and Åsberg Depression Rating Scale. J Psychosom Res 67(4):325-332

26. Post MW, van de Port IG, Kap B, Berdenis van Berlekom SH (2009) Development and validation of the Utrecht Scale for Evaluation of Clinical Rehabilitation (USER). Clin Rehabilit 23(10):909-917. https://doi.org/10.1177/0269215509341524

27. Post MW, van der Zee CH, Hennink J, Schafrat CG, VisserMeily JM, van Berlekom SB (2012) Validity of the utrecht scale for evaluation of rehabilitation-participation. Disabil Rehabil 34(6):478-485. https://doi.org/10.3109/09638288.2011.608148

28. van der Zee CH, Baars-Elsinga A, Visser-Meily JM, Post MW (2013) Responsiveness of two participation measures in an outpatient rehabilitation setting. Scand J Occup Therapy 20(3):201208. https://doi.org/10.3109/11038128.2012.754491

29. van der Zee CH, Kap A, Rambaran Mishre R, Schouten EJ, Post MW (2011) Responsiveness of four participation measures to changes during and after outpatient rehabilitation. J Rehabil Med 43(11):1003-1009. https://doi.org/10.2340/16501977-0879

30. Shih MM, Rogers JC, Skidmore ER, Irrgang JJ, Holm MB (2009) Measuring stroke survivors' functional status independence: five perspectives. Am J Occup Therapy Off Publ Am Occup Therapy Assoc 63(5):600-608. https://doi.org/10.5014/ajot.63.5.600

31. Xu X, Tang R, Zhang L, Cao Z (2019) Altered topology of the structural brain network in patients with post-stroke depression. Front Neurosci 13:776. https://doi.org/10.3389/fnins.2019.00776

32. Siegel JS, Ramsey LE, Snyder AZ, Metcalf NV, Chacko RV, Weinberger K, Baldassarre A, Hacker CD, Shulman GL, Corbetta M (2016) Disruptions of network connectivity predict impairment in multiple behavioral domains after stroke. Proc Natl Acad Sci USA 113(30):E4367-4376. https://doi.org/10.1073/pnas.15210 83113

33. Lim JS, Kang DW (2015) Stroke connectome and its implications for cognitive and behavioral sequela of stroke. J stroke 17(3):256267. https://doi.org/10.5853/jos.2015.17.3.256

34. Mole JA, Demeyere N (2018) The relationship between early post-stroke cognition and longer term activities and participation: a systematic review. Neuropsychol Rehabilit. https://doi. org/10.1080/09602011.2018.1464934

35. Party ISW (2012) National clinical guideline for stroke, vol 20083. Citeseer

36. Moulaert VR, van Heugten CM, Winkens B, Bakx WG, de Krom MC, Gorgels TP, Wade DT, Verbunt JA (2015) Early neurologically-focused follow-up after cardiac arrest improves quality of life at 1 year: a randomised controlled trial. Int J Cardiol 193:8-16

37. Moulaert VR, Goossens M, Heijnders IL, Verbunt JA, van Heugten CM (2016) Early neurologically focused follow-up after cardiac arrest is cost-effective: a trial-based economic evaluation. Resuscitation 106:30-36

38. Rogers JM, Foord R, Stolwyk RJ, Wong D, Wilson PH (2018) General and domain-specific effectiveness of cognitive remediation after stroke: systematic literature review and meta-analysis. Neuropsychol Rev 28(3):285-309. https://doi.org/10.1007/s1106 5-018-9378-4

39. Hackett ML, Anderson CS, House A, Xia J (2008) Interventions for treating depression after stroke. Cochrane Datab Syst Rev 4:Cd003437. https://doi.org/10.1002/14651858.CD003437.pub3

40. Knapp P, Campbell Burton CA, Holmes J, Murray J, Gillespie D, Lightbody CE, Watkins CL, Chun HY, Lewis SR (2017) Interventions for treating anxiety after stroke. Cochrane Datab Syst Rev 5:Cd008860. https://doi.org/10.1002/14651858.CD008860.pub3 